\title{
WELCOME TO ALBUQUERQUE
}

\section{The West Coast Meeting Adds A New Dimension To The MRS}

It is a great pleasure for me to welcome you to Albuquerque for the first annual MRS West Coast Meeting. This conference adds an entirely new dimension to the activities of the Materials Research Society. In the past, the Society sponsored a yearly meeting in Boston in November of each year. In a few short years that meeting has become the premier conference in the world for materials professionals. The increased participation by individuals in the Materials Research Society and the demand among its members for more topical symposia in key areas of materials science made it necessary for the Society to establish a second yearly meeting. The meeting in Albuquerque is the first of these. Although this meeting will be smaller in terms of attendance and the number of topical symposia offered, we expect the West Coast meeting to grow rapidly and, in a few years, to be comparable in size with the . Boston meeting. Plans for a second West Coast meeting are discussed elsewhere in this number of the BULLETIN by President-Elect Elton Kaufmann.

\section{Vital Information-Sharing Events}

The Materials Research Society is the foremost technical society in the world for those professionals concerned with the forefront areas of materials science. The MRS symposia are interdisciplinary and they span a range from basic research to applications. The goal for each symposium is to insure that all possible physical, chemical, and engineering insights are considered for the topic being examined. The Society has earned a reputation as the sponsor of the most vital information-sharing events within the materials community. You can be assured that the same standards of technical program selection that have earned us our reputation will be applied to program selection for the West Coast meetings.

Organizing a meeting of the size of the Albuquerque Meeting requires enormous efforts on the part of dedicated individuals. The Meeting Chairpersons for this meeting-Gordon Pike, Sandia National Labs, Noble Johnson, Xerox, and Ross Lemons, Los Alamos National Lab-have done a superb job in selecting the technical program. They had far less time to accomplish this task than is customary for planning the Boston meeting.

Chairmen of the individual symposia are to be commended as well for the jobs they did in organizing the technical symposia. The MRS also owes a debt of gratitude to Rod Quinn and his colleagues at Sandia and in the Albuquerque area for providing the local arrangements for the conference.

I am sure you will find this meeting to be both rewarding and stimulating. In addition, the Albuquerque area exhibits a unique blend of beauty and charm, and I hope that you will take the time to enjoy the social and recreational opportunities which the area offers to you.

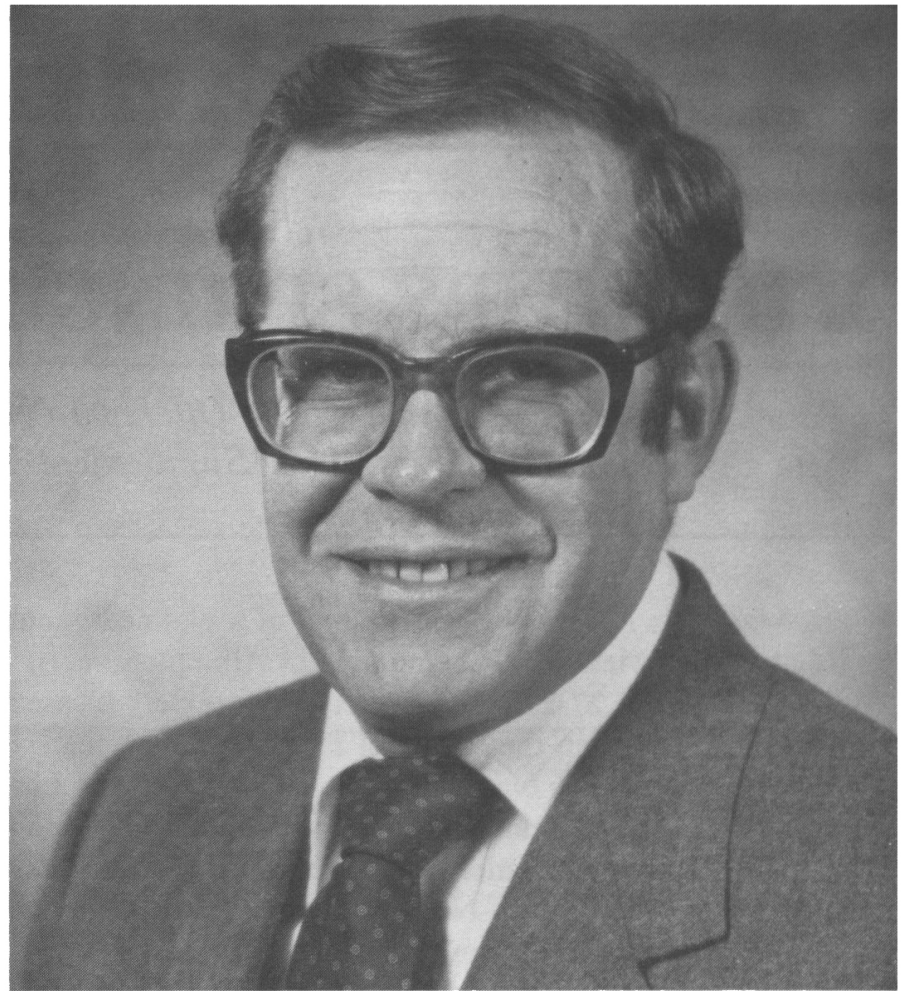

\section{"WOODY" WHITE}

\section{Looking Ahead}

The Albuquerque and San Francisco meetings are not the only innovations your Society has made. Beginning in this issue of the BULLETIN, we are adding a Calendar of Events of interest to the materials community. This has been prepared by Julia Phillips, Chairperson of our new Task Force on Publicity and Public Relations, who has also agreed to lend her time, talent, and energy to make the BULLETIN even more timely and informative than it has been. Past President Harry Leamy is also continuing to play a leading role in the preparation of the BULLETIN. I appreciate their work very much, and I'm sure each of us finds the BULLETIN a particularly useful benefit of MRS membership.

We are also implementing a major Equipment Exhibition as part of the Annual Meeting in Boston. It is reported elsewhere in these pages. This is part of our expansion of the Boston Meeting-already the best conference for materials professionals - to make it increasingly interesting and valuable. In the months to come we will introduce many other exciting new developments which will further enhance the Society's service to its members.

\section{C.W. "Woody" White President}

